\title{
Studies on cluster, salt and molecular complex of zinc-quinolinate
}

\author{
PRITHIVIRAJ KHAKHLARY and JUBARAJ B BARUAH* \\ Department of Chemistry, Indian Institute of Technology Guwahati, Guwahati 781 039, India \\ e-mail: juba@iitg.ernet.in
}

MS received 7 October 2013; accepted 11 July 2014

\begin{abstract}
Reactions of zinc halides with 8-hydroxyquinoline (hydroxQ) in equimolar ratio were carried out in different solvents. Respective solvates of tetranuclear clusters, namely $\left[\mathrm{Zn}_{4}(\mathrm{oxyQ})_{6} \mathrm{X}_{2}\right]$. (solvent) ${ }_{2}$, (when $\mathrm{X}$ $=\mathrm{Cl}$, Solvent $=$ dimethylformamide (1), dimethylacetamide (2) and dimethysulphoxide (3); $\mathrm{X}=\mathrm{Br}$, solvent $=$ dimethylformamide (4), oxyQ $=$ quinolinate anion) were obtained. Bond parameters of these isostructural clusteres 1-4 are compared from their single crystal structures. Anhydrous form of the cluster have porous packing and is thermally stable below $250^{\circ} \mathrm{C}$. Surface area of the clusters $\mathbf{1}$ and $\mathbf{4}$ are 8.933 and $6.172 \mathrm{~m}^{2} / \mathrm{g}$, respectively. Complexes $\mathbf{1}$ and $\mathbf{4}$ can be reversibly hydrated, which is reflected in colour changes. The reaction of zinc chloride with 8-hydroxyquinoline in equimolar ratio followed by crystallization from water gave salt $(\text { HhydroxQ })_{2}\left[\mathrm{ZnCl}_{4}\right](5)$ and a similar reaction followed by crystallization from 3-methylpyridine (3mepy) resulted in the molecular complex $\left[\mathrm{Zn}(\text { oxyQ })_{2}(3\right.$ mepy $\left.)\right]$. $\left[\mathrm{Zn}(\text { oxyQ })_{2}(3 \text { mepy })_{2}\right] .3 \mathrm{H}_{2} \mathrm{O}(\mathbf{6})$. Complex $\mathbf{5}$ is formed from a hydrolytic equilibrium of water with zinc chloride yielding tetrachloro zinc anion and zinc hydroxide. Taking advantage of this reaction, a composite material of $\mathrm{ZnO@complex} \mathbf{5}$ exhibiting dual fluorescence at 450 and $575 \mathrm{~nm}$ on excitation at $390 \mathrm{~nm}$ was prepared. Fluorescence emission properties of all the complexes in solid state are compared with fluorescence emission of the ligand.
\end{abstract}

Keywords. Zinc-clusters; molecular complex; hydrolytic equilibrium; zinc oxide; porous material.

\section{Introduction}

Zinc carboxylates are widely used as metallo-organic frameworks ${ }^{1-10}$ for gas absorption. Such studies require information on the ability to retain framework structure under drastic conditions after removal of solvated species. Covalently linked compounds of zinc carboxylates with giant structures are useful in these studies. ${ }^{11,12}$ However, an understanding of the packing of solvates of large zinc clusters is essential as solvents may act as filler of voids between molecules. This effect may help in reversible exchange to pave way for preparing useful porous materials. Since zinc ions can form varieties of neutral clusters ${ }^{13-16}$ and zinc quinolinate complexes are useful as optical material, ${ }^{17-19}$ we report here a series solvates of tetra-nuclear zinc 8oxyquinolinate clusters along with their hydration and determination of surface area. We prepared a series of solvates of tetra-nuclear clusters of zinc with halide as the terminal ligand as shown in figure 1 . The advantage of the 8-hydroxyquinline as ligand is due to its reported ability to form tetra-nuclear clusters having carboxylate terminal groups..$^{20,21}$ Moreover, while understanding the hydrolytic equilibrium of zinc chloride in presence of 8-hydroxyquinoline we are able to

\footnotetext{
*For correspondence
}

encapsulate zinc oxide by a zinc complex, which in turn displays novel fluorescence property.

\section{Experimental}

All reagents were obtained from Sigma Aldrich (USA) and used as received. IR spectra were recorded on a Perkin-Elmer Spectrum One FT-IR spectrometer with $\mathrm{KBr}$ pallets in the range of $4000-400 \mathrm{~cm}^{-1}$. ${ }^{1} \mathrm{HNMR}$ data were recorded with a Varian $400 \mathrm{MHz}$ FTNMR spectrometer. Powder X-ray diffraction (XRD) patterns were recorded on a Bruker D8 Advance (Germany)

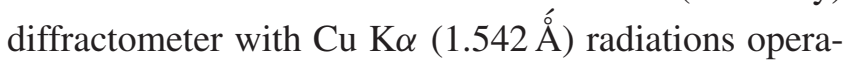
ted at $40 \mathrm{kV}$ and $40 \mathrm{~mA}$ on glass surface of an air-dried sample. Solid state fluorescence emission spectra were measured on a Horiba Jobin Yvon Fluoromax-4 spectrofluorimeter. Surface analysis was performed using a Quantachrome, Model: Autosorb-IQ MP surface analyser.

\section{$2.1 X$ - ray crystallography}

X-ray single crystal diffraction data for all the compounds were collected on Oxford SuperNova diffractometer. Data refinement and cell reductions were carried out by CrysAlisPro. ${ }^{41}$ Structures were solved by direct methods and refined by full-matrix least-squares 


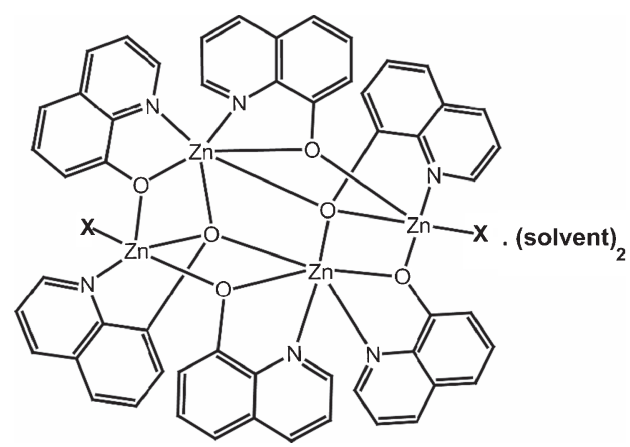

where $\mathrm{X}=\mathrm{Cl}$ or $\mathrm{Br}$, solvent $=\mathrm{DMF}$, DMA or DMSO

Figure 1. Tetra-nuclear zinc-8-oxyquinolate cluster.

calculations using SHELXTL software. ${ }^{42}$ All the non-H atoms were refined in the anisotropic approximation against $F^{2}$ of all reflections. Crystal parameters of the crystals are shown in table 1.

\subsection{Synthesis of zinc complexes}

To a solution of 8-hydroxyquinoline $(0.31 \mathrm{~g}, 2 \mathrm{mmol})$ in methanol $(20 \mathrm{ml})$ zinc chloride $(0.28 \mathrm{~g}, 2 \mathrm{mmol})$ was added and stirred for 15-20 min. A white precipitate was formed which was filtered and recrystallized from DMF to obtain complex 1. Similar recrystallization of the white precipitate from DMA and DMSO yielded their corresponding solvates. DMF solvate (1): Yield $\sim 45 \%$ (with respect to zinc). IR (KBr, $\mathrm{cm}^{-1}$ ): 3392(s), 2919(w), 2851(w), 1624(m), 1577(m), 1499(s), 1467(s), 1421(w), 1389(s), 1371(s), 1327 (s), 1283 (w), $1240(\mathrm{w}), 1109(\mathrm{~s}), 1033(\mathrm{w}), 820(\mathrm{w}), 783(\mathrm{w})$, $742(\mathrm{~m}), 620(\mathrm{w})$. DMA solvate (2): yield $\sim 48 \%$ (with respect to zinc). IR $\left(\mathrm{KBr}, \mathrm{cm}^{-1}\right): 3372(\mathrm{~s}), 2919(\mathrm{w})$, 2851(w), 1628 (m), 1602 (m), 1577 (m), 1499 (s), 1466 (s), 1421(w), 1389 (s), 1371(s), 1327 (s), $1282(\mathrm{w})$, $1240(\mathrm{w}), 1109(\mathrm{~s}), 1031(\mathrm{w}), 820(\mathrm{w}), 785(\mathrm{w}), 742(\mathrm{~m})$, $640(\mathrm{w}), 596(\mathrm{w}), 502(\mathrm{w})$. DMSO solvate (3): Yield $\sim 45 \%$ (with respect to zinc). IR $\left(\mathrm{KBr}, \mathrm{cm}^{-1}\right): 3378$ (s), 2918 (w), 1618(m), 1603 (m), 1577 (m), 1500 (s), 1467 (s), $1399(\mathrm{w}), 1390(\mathrm{~s}), 1371(\mathrm{~s}), 1327(\mathrm{~s}), 1283(\mathrm{w})$, 1241(w), 1110 (m) 1033 (w), 850 (w), 820 (w), 780 (w), $743(\mathrm{~s}), 640(\mathrm{w}), 502(\mathrm{w}) .{ }^{1} \mathrm{HNMR}$ (DMSO- $d_{6}, 400$ $\mathrm{MHz}), 8.60$ (s, 3H), 8.33 (d, J=8 Hz, 3H), 7.47 (s, 3H), $7.30(\mathrm{~s}, 3 \mathrm{H}), 6.93(\mathrm{q}, J=6.8 \mathrm{~Hz}, 6 \mathrm{H}), 2.04(\mathrm{~s}, 6 \mathrm{H})$.

A procedure similar to that of $\mathbf{1}$ was used for preparation of complex $\mathbf{4}$ in which zinc bromide was used in place of zinc chloride in DMF $(10 \mathrm{ml})$. Yield $\sim 45 \%$ (with respect to zinc). IR ( $\left.\mathrm{KBr}, \mathrm{cm}^{-1}\right): 3190$ (s), 1644 (m), 1601(m), 1577 (m), 1499 (s), 1456 (s), 1421(w), 1373(s), 1325(s), 1280 (w), 1137 (w), 1105(s), 1067 (w), $1032(\mathrm{w}), 909(\mathrm{w}), 821(\mathrm{~m}), 787$ (m), $742(\mathrm{~m})$, 641(w), $600(\mathrm{w}), 545(\mathrm{w}), 499(\mathrm{w})$.
Salt 5 was obtained by a procedure similar to that of $\mathbf{1}$ but water was used as solvent to dissolve the precipitate. Yield $\sim 35 \%$ (with respect to zinc). IR ( $\mathrm{KBr}$, $\left.\mathrm{cm}^{-1}\right)$ : 3453(w), 3056(w), 2933(w), 2539(w), 1627(w), 1581(m), 1531(w), 1499(s), 1467(s), 1428(w), 1382(s), 1359(s), 1324(s), 1276(m), 1241(m), 1228(w), 1180(w), 1106(s), 1022(s), 916(w), 823(s), 786(s), 755(s), 646(w), 553(w), 514(m).

A procedure similar to that of $\mathbf{1}$ was used to prepare molecular complex 6. However, 3-picoline was used in excess to dissolve the precipitate. Yield $\sim 60 \%$ (with respect to zinc). \%. IR $\left(\mathrm{KBr}, \mathrm{cm}^{-1}\right): 3323(\mathrm{~s}), 3044(\mathrm{w})$, 1581(m), 1495 (m), 1464 (s), 1422 (w), 1389 (s), 1327 (s), $1283(\mathrm{w}), 1232(\mathrm{w}), 1109(\mathrm{~m}), 1056(\mathrm{w}), 1031(\mathrm{w})$, $821(\mathrm{~m}), 791(\mathrm{~m}), 735(\mathrm{~m}), 705(\mathrm{w}), 640(\mathrm{w}), 500(\mathrm{w})$. ${ }^{1} \mathrm{HNMR}$ (DMSO- $\left.d_{6}, 400 \mathrm{MHz}\right), 8.78(\mathrm{t}, J=2.8 \mathrm{~Hz}$, $3 \mathrm{H}), 8.36$ (q, $J=1.6 \mathrm{~Hz}, 4 \mathrm{H}), 7.57$ (q, $J=4 \mathrm{~Hz}, 3 \mathrm{H})$, 7.44 (q, $J=8 \mathrm{~Hz}, 2 \mathrm{H}), 7.29$ (d, $J=8 \mathrm{~Hz}, 2 \mathrm{H}), 7.02$ (d, $J=7.2 \mathrm{~Hz}, 3 \mathrm{H}), 2.29$ (s, 6H).

\section{Results and Discussion}

Tetra-nuclear zinc 8-oxyquinolinate clusters possessing chloride and bromide as terminal ligands were synthesised by reacting corresponding salt of zinc with 8hydroxyquinoline in different solvents which is shown in equation 1 . The structure of each solvated cluster was determined to ascertain the identity of the complexes and packing patterns.

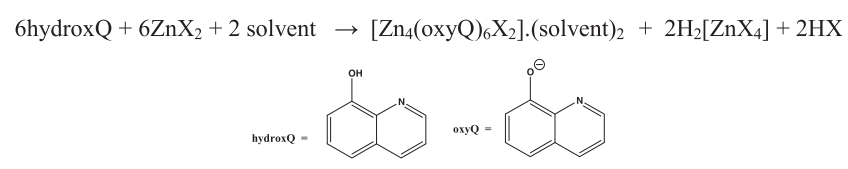

when $\mathrm{X}=\mathrm{Cl}$, solvent $=\mathrm{DMF}(\mathbf{1}) ; \mathrm{X}=\mathrm{Cl}$, solvent $=$ DMA (2); $\mathrm{X}=\mathrm{Cl}$, solvent $=\mathrm{DMSO}(\mathbf{3}) ; \mathrm{X}=\mathrm{Br}$, solvent $=\operatorname{DMF}(\mathbf{4})$.

Clusters 1-4 are isostructural, each belong to P-1 space group and have unit cell volume 1457.18(14), 1482.62(15), 1445.71(18) and 1470.82(16) $\AA^{3}$, respectively. The respective crystal densities are 1.531, 1.536, 1.555 and $1.617 \mathrm{~g} / \mathrm{cm}^{3}$. Clusters have similar tetra-nuclear zinc core as shown in figure $2 a$. Metal ions in the clusters are in two different types of environments. The zinc sites holding the halide ions are penta-coordinated while the other two zinc sites are hexa-coordinated. The metal ligand bond distances are comparable to the reported complexes with acetate as auxiliary ligands. ${ }^{20}$ Comparisons of various metal ligand bond distances are listed in supporting information. Packing patterns clusters are guided by $\mathrm{C}-\mathrm{H}^{\cdots} \pi$ and $\mathrm{C}-\mathrm{H}^{\cdots} \mathrm{X}$ interactions. One illustrative example is shown in figure $2 b$ and $c$. 
Table 1. Crystal parameters of the complexes 1-6.

\begin{tabular}{|c|c|c|c|c|c|c|}
\hline $\begin{array}{l}\text { Compound No. } \\
\text { Formulae }\end{array}$ & $\underset{\mathrm{C}_{60} \mathrm{H}_{50} \mathrm{Cl}_{2} \mathrm{~N}_{8} \mathrm{O}_{8} \mathrm{Zn}_{4}}{\mathbf{1}}$ & 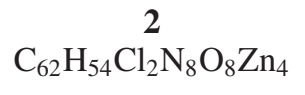 & $\frac{\mathbf{3}}{\mathrm{C}_{58} \mathrm{H}_{48} \mathrm{Cl}_{2} \mathrm{~N}_{6} \mathrm{O}_{8} \mathrm{~S}_{2} \mathrm{Zn}_{4}}$ & $\underset{\mathrm{C}_{60} \mathrm{H}_{50} \mathrm{Br}_{2} \mathrm{~N}_{8} \mathrm{O}_{8} \mathrm{Zn}_{4}}{\mathbf{4}}$ & $\underset{\mathrm{C}_{18} \mathrm{H}_{16} \mathrm{Cl}_{4} \mathrm{~N}_{2} \mathrm{O}_{2} \mathrm{Zn}}{\mathbf{5}}$ & $\stackrel{\mathbf{6}}{\mathrm{C}_{78} \mathrm{H}_{68} \mathrm{~N}_{10} \mathrm{O}_{9} \mathrm{Zn}_{3}}$ \\
\hline Mol. wt. & 1343.46 & 1371.51 & 1353.52 & 1432.38 & 499.50 & 1485.53 \\
\hline CCDC No. & 960180 & 960179 & 960181 & 960177 & 960182 & 960178 \\
\hline Crystal system & Triclinic & Triclinic & Triclinic & Triclinic & Monoclinic & Monoclinic \\
\hline Space group & $P-1$ & $P-1$ & $P-1$ & $P-1$ & $C 2 / c$ & $P 2 / c$ \\
\hline Temperature (K) & $296(2)$ & $296(2)$ & $296(2)$ & $296(2)$ & $296(2)$ & $296(2)$ \\
\hline Wavelength $(\AA)$ & 0.71073 & 0.71073 & 0.71073 & 0.71073 & 0.71073 & 0.71073 \\
\hline$a(\AA)$ & $11.4278(7)$ & $11.2931(7)$ & $11.5945(6)$ & $11.3662(7)$ & $15.2315(10)$ & $22.9887(12)$ \\
\hline$b(\AA)$ & 12.5311(6) & $12.6163(8)$ & $12.4479(9)$ & $12.5613(8)$ & $8.1375(9)$ & 8.3971(4) \\
\hline$c(\AA)$ & $12.6744(7)$ & $12.7410(7)$ & $12.5482(10)$ & $12.6119(8)$ & $16.742(2)$ & $18.0997(8)$ \\
\hline$\alpha\left(^{\circ}\right)$ & $101.688(4)$ & $102.346(5)$ & $99.560(7)$ & $101.500(5)$ & 90.00 & 90.00 \\
\hline$\beta\left(^{\circ}\right)$ & $110.189(5)$ & $111.205(5)$ & $114.464(7)$ & $109.660(6)$ & $91.413(9)$ & $93.958(4)$ \\
\hline$\gamma\left({ }^{\circ}\right)$ & $112.178(5)$ & 109.004(5) & 109.975(6) & $111.242(6)$ & 90.00 & 90.00 \\
\hline $\mathrm{V}\left(\AA^{3}\right)$ & $1457.18(14)$ & $1482.62(15)$ & $1445.71(18)$ & $1470.82(16)$ & $2074.5(4)$ & $3485.6(3)$ \\
\hline $\mathrm{Z}$ & 1 & 1 & 1 & 1 & 4 & 2 \\
\hline Density/gcm ${ }^{-3}$ & 1.531 & 1.536 & 1.555 & 1.617 & 1.599 & 1.415 \\
\hline Abs. Coeff. $/ \mathrm{mm}^{-1}$ & 1.780 & 1.751 & 1.863 & 3.031 & 1.715 & 1.091 \\
\hline Abs. correction & multi-scan & None & multi-scan & multi-scan & multi-scan & none \\
\hline $\mathrm{F}(000)$ & 684 & 700 & 688 & 720 & 1008 & 1536 \\
\hline Total No. of reflections & 5259 & 5364 & 5231 & 5323 & 1870 & 6301 \\
\hline Reflections, $I>2 \sigma(\mathrm{I})$ & 4012 & 4054 & 3572 & 3993 & 1126 & 4013 \\
\hline \multirow[t]{2}{*}{$\operatorname{Max} .2 \theta\left(^{\circ}\right)$} & 50.50 & 50.50 & 50.50 & 50.50 & 50.48 & 50.50 \\
\hline & $-13 \leq \mathrm{h} \leq 13$ & $-13 \leq h \leq 13$ & $-13 \leq h \leq 13$ & $-13 \leq \mathrm{h} \leq 13$ & $-18 \leq \mathrm{h} \leq 9$ & $-27 \leq \mathrm{h} \leq 27$ \\
\hline \multirow[t]{2}{*}{ Ranges $(h, k, l)$} & $-15 \leq \mathrm{k} \leq 11$ & $-15 \leq \mathrm{k} \leq 15$ & $-14 \leq \mathrm{k} \leq 14$ & $-15 \leq \mathrm{k} \leq 14$ & $-9 \leq \mathrm{k} \leq 9$ & $-10 \leq \mathrm{k} \leq 7$ \\
\hline & $-15 \leq 1 \leq 15$ & $-15 \leq 1 \leq 15$ & $-15 \leq 1 \leq 15$ & $-15 \leq 1 \leq 13$ & $-20 \leq 1 \leq 8$ & $-21 \leq 1 \leq 20$ \\
\hline Completeness to $2 \theta(\%)$ & 0.999 & 0.999 & 0.999 & 0.999 & 0.992 & 0.998 \\
\hline Data/Restraints/Parameters & $5259 / 0 / 372$ & $5364 / 32 / 382$ & $5231 / 0 / 363$ & $5323 / 0 / 372$ & $1870 / 0 / 128$ & $6301 / 7 / 467$ \\
\hline $\operatorname{Goof}\left(F^{2}\right)$ & 1.035 & 1.034 & 1.049 & 1.028 & 1.043 & 1.052 \\
\hline $\mathrm{R}$ indices $[I>2 \sigma(\mathrm{I})]$ & 0.0422 & 0.0548 & 0.0615 & 0.0421 & 0.0413 & 0.0647 \\
\hline$R$ indices (all data) & 0.0610 & 0.0751 & 0.0936 & 0.0638 & 0.0663 & 0.1058 \\
\hline
\end{tabular}



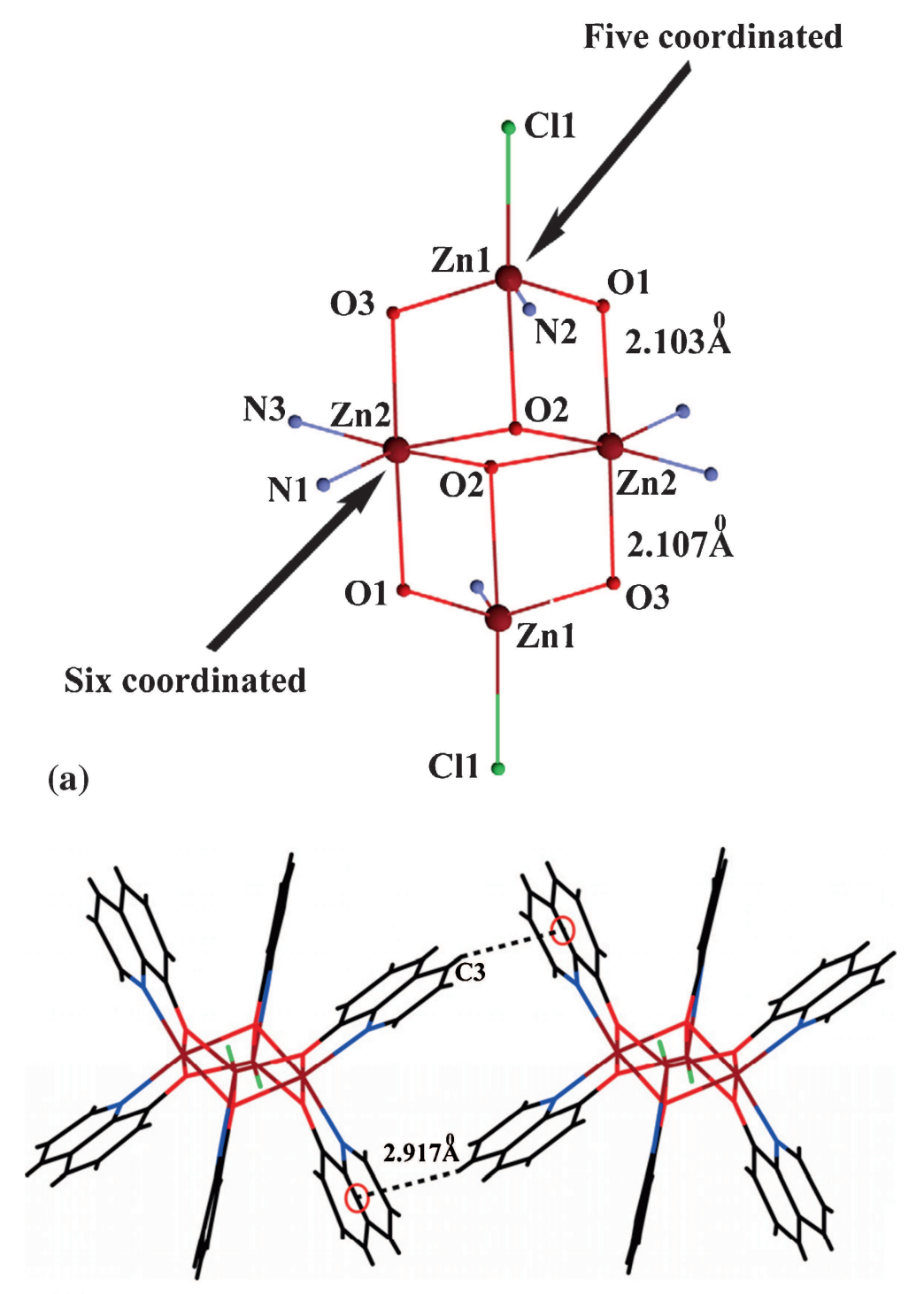

(b)

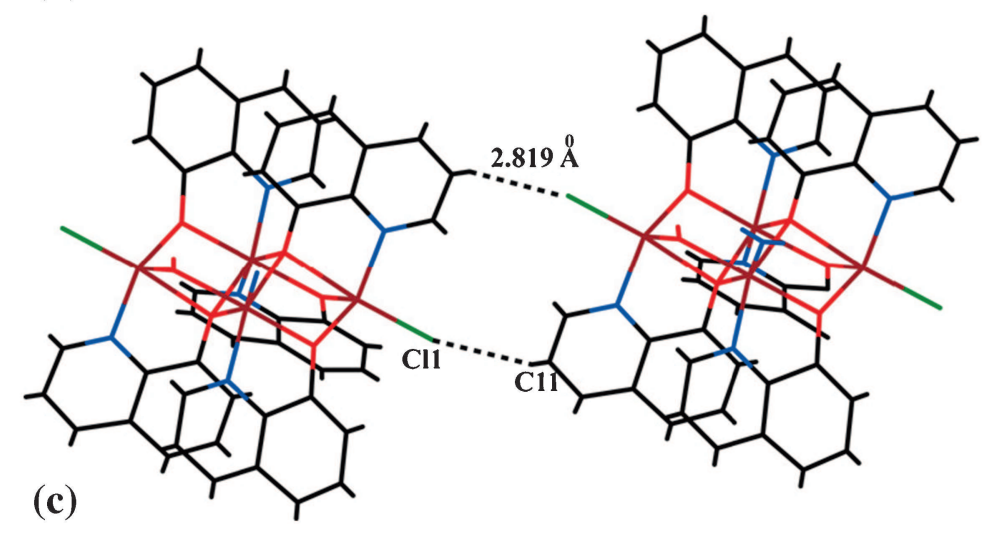

Figure 2. (a) Two different coordination environment in $\left[\mathrm{Zn}_{4}(\text { oxyQ })_{6}\right.$ $\mathrm{Cl}_{2}$ ] core; (b) $\mathrm{C}-\mathrm{H}^{*} \pi$ interactions and (c) $\mathrm{C}-\mathrm{H}{ }^{\cdots} \mathrm{Cl}$ interactions in complex 1 .

The $\mathrm{C} 11-\mathrm{H}^{\cdots} \mathrm{Cl}$ has the hydrogen bond donor-acceptor distance $\mathrm{d}_{\mathrm{H} 11} \ldots \mathrm{Cl} 12.819 \AA$ and angle $<\mathrm{C} 11-\mathrm{H} 11 \cdots \mathrm{Cl} 1$, $130.1^{\circ}$. Distance between the centriod of the $\pi$-cloud of quinoline and the $\mathrm{H}$ of $\mathrm{C} 3-\mathrm{H} 3$ bond is $2.92 \AA$. The solvent molecules are held loosely by weak interactions; in the case of dimethylformamide (DMF), the interactions are through $\mathrm{C}-\mathrm{H}^{\cdots} \mathrm{O}$ interactions; whereas DMA are held by $\mathrm{C}-\mathrm{H}^{\cdots}{ }^{\prime \prime} \pi$ interactions. Due to loose 
Table 2. Comparison of bond lengths and bond angles of complexes 1-3.

\begin{tabular}{|c|c|c|c|c|c|c|c|}
\hline & Length $(\AA)$ & Length $(\AA)$ & Length $(\AA)$ & & Angle $\left(^{\circ}\right)$ & Angle $\left(^{\circ}\right)$ & Angle $\left(^{\circ}\right)$ \\
\hline Bond & Complex 1 & Complex 2 & Complex $\mathbf{3}$ & Bond angle & Complex 1 & Complex 2 & Complex $\mathbf{3}$ \\
\hline Zn1-Cl1 & $2.283(11)$ & $2.287(2)$ & $2.284(2)$ & Cl1-Zn1-O1 & $108.47(8)$ & $108.02(14)$ & $109.83(13)$ \\
\hline Zn1-O1 & $2.004(4)$ & $2.001(5)$ & $1.993(5)$ & $\mathrm{Zn} 1-\mathrm{O} 2-\mathrm{Zn} 2$ & $95.66(9)$ & $95.63(17)$ & $106.8(2)$ \\
\hline $\mathrm{Zn} 1-\mathrm{O} 2$ & $2.313(2)$ & $2.303(4)$ & $2.324(4)$ & $\mathrm{Cl1}-\mathrm{Zn} 1-\mathrm{O} 2$ & $171.98(8)$ & 171.73(12) & $171.33(12)$ \\
\hline Zn1-O3 & $2.007(3)$ & $2.013(5)$ & $2.018(5)$ & Cl1-Zn1-O3 & $106.40(8)$ & $106.65(14)$ & $105.23(13)$ \\
\hline Zn1-N2 & $2.101(4)$ & $2.108(6)$ & $2.105(5)$ & $\mathrm{Zn} 1-\mathrm{O} 2-\mathrm{Zn} 2 \mathrm{a}$ & $96.99(10)$ & $97.00(16)$ & $97.82(15)$ \\
\hline $\mathrm{Zn} 2-\mathrm{O} 1$ & $2.103(2)$ & $2.103(4)$ & $2.106(4)$ & Cl1-Zn1-N2 & $97.56(10)$ & $97.26(18)$ & 77.41(17) \\
\hline $\mathrm{Zn} 2-\mathrm{O} 2$ & $2.136(3)$ & $2.141(5)$ & $2.126(5)$ & $\mathrm{Zn} 2-\mathrm{O} 2-\mathrm{Zn} 2 \mathrm{a}$ & $100.30(11)$ & $100.29(15)$ & $99.96(14)$ \\
\hline \multirow[t]{2}{*}{$\mathrm{Zn} 2-\mathrm{N} 1$} & $2.089(4)$ & $2.082(6)$ & $2.091(6)$ & $\mathrm{Zn} 1-\mathrm{O} 3-\mathrm{Zn} 2 \mathrm{a}$ & 107.04(13) & 106.8(2) & $96.68(16)$ \\
\hline & & & & Zn1-O1-Zn2 & 106.93(13) & $106.9(2)$ & $107.0(2)$ \\
\hline
\end{tabular}

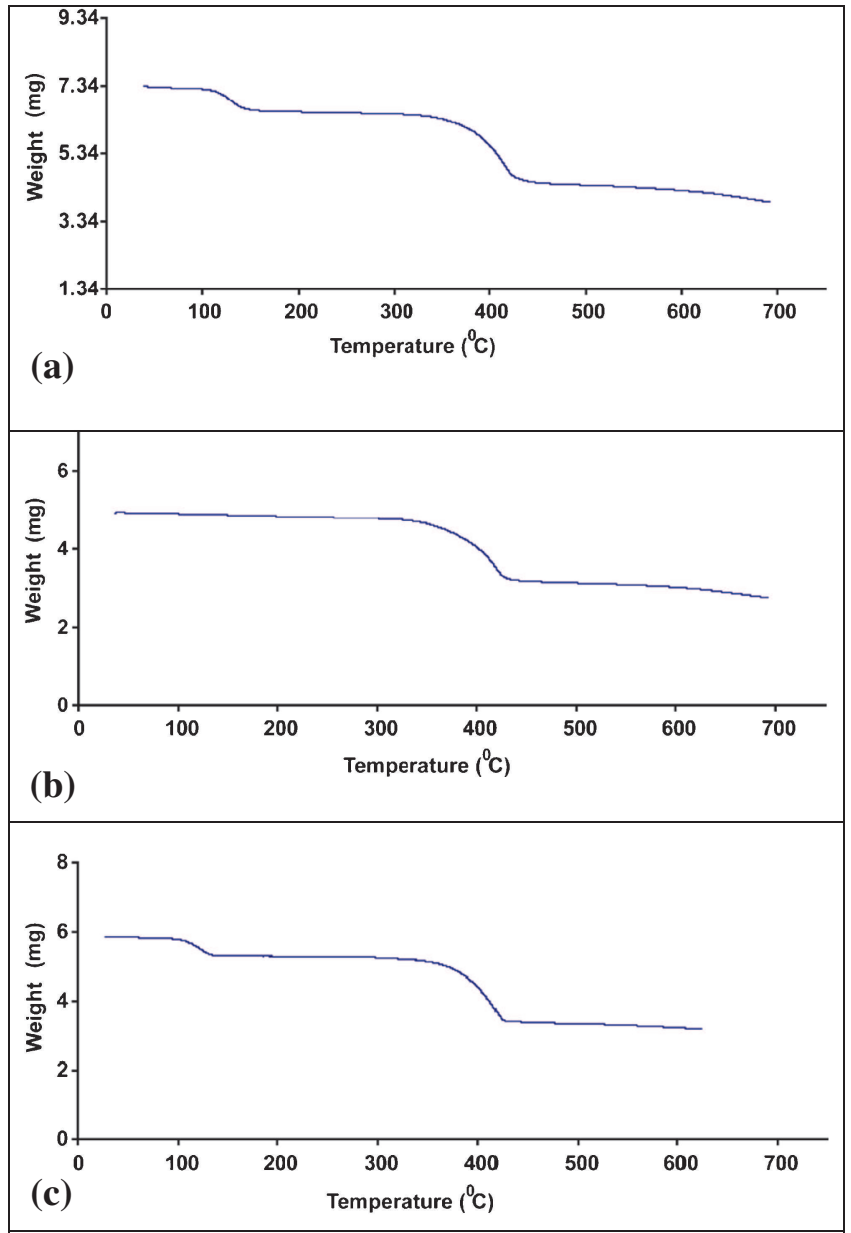

Figure 3. Thermogravimetry of (a) Cluster 1; (b) cluster 1 heated at $200^{\circ} \mathrm{C}$; (c) desolavted cluster $\mathbf{1}$ after exposing to moisture (heating rate in each case $5^{\circ} \mathrm{C}$ per minute).

$\left[\mathrm{Zn}_{4}(\text { oxyQ })_{6} \mathrm{Cl}_{2}\right]$. (solvent $)_{2} \rightarrow\left[\mathrm{Zn}_{4}(\text { oxyQ })_{6} \mathrm{Cl}_{2}\right] \rightarrow\left[\mathrm{Zn}_{4}(\text { oxyQ })_{3}(\mathrm{OH})(\mathrm{O}) \mathrm{Cl}_{2}\right]$

Scheme 1. Thermal decomposition of the clusters 1-3.

binding of the solvent, these clusters lose their solvent molecules at relatively low temperature. We have compared the bond distances and bond angles of zinc atoms in clusters 1-4. Table 2 presents a comparison of the effect of solvents in the geometry of the tetra-nuclear clusters $\mathbf{1}, \mathbf{3}$. Clusters $\mathbf{1}$ and $\mathbf{2}$ have DMF and DMA as the solvent of crystallization, both are homologous, and accordingly we do not see much difference in the structure of the host. However, cluster 3 has DMSO as solvent of crystallization; it has a clear difference in the $\mathrm{Zn} 1-\mathrm{O} 2-\mathrm{Zn} 2$ bond angle at one face without significantly affecting the analogous bond on the other face. Thus, the solvent causes slight distortion of one face of the cluster. On the other hand, clusters 1 and 4 have DMF as solvent of crystallization but have different anions; former has two chlorides, whereas latter has two bromides. The comparison of the bond parameters between these two clearly shows that the difference in metal halogen bonds is obvious from the difference in atomic radius of the halides. There are differences between the $\mathrm{Zn} 1-\mathrm{O} 2$ and $\mathrm{Zn} 1-\mathrm{O} 3$ distances, in the case of cluster 4 . In both cases, the halogens project away and do not interfere in the knitting of the cluster, in spite of the change in metal-oxygen bond distances of the site where the halides are attached. This indicates that the packing effect as well as electro-negativity difference between the halides play a role in giving shape to the geometry of the clusters.

Thermogram of the DMF solvate $\mathbf{1}$ is shown in figure $3 a$. Weight loss at $90-137^{\circ} \mathrm{C}$ occurs due to loss of two molecules of DMF (theoretical 10. $9 \%$ and found $8.9 \%$ ) and the compound is thermally stable up to $350^{\circ} \mathrm{C}$. Thermal decomposition of the clusters can be correlated by scheme 1. It involves two steps; first is loss of solvent, followed by decomposition of the complex to lose three 8-hydroxyquinolinates. For complex 1, the calculated weight loss to form a composition $\left[\mathrm{Zn}_{4}(\mathrm{oxyQ})_{3}(\mathrm{OH})(\mathrm{O}) \mathrm{Cl}_{2}\right]$ is $41.1 \%$, whereas weigh loss at $350-450^{\circ} \mathrm{C}$ was found to be $42.7 \%$. Cluster 4 also has shown a similar trend of thermal decomposition. The IR spectra of cluster 4 after heating at $480^{\circ} \mathrm{C}$ was recorded, which showed the IR-stretching frequencies of the 


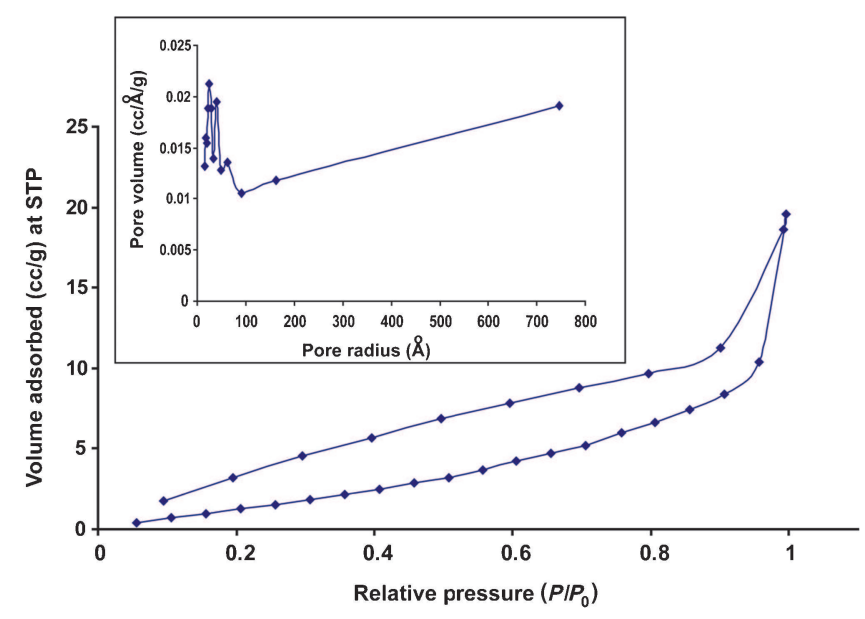

Figure 4. Nitrogen gas adsorption isotherm at standard temperature and pressure for complex $\mathbf{1}$ and pore size distribution (inset).

oxyquinolinate part (refer to supplementary figure 6S). This suggests that at $480^{\circ} \mathrm{C}$, a portion of the oxyquinolinate ligand remains with zinc ions. Since clusters on heating led to partial loss of quinolinate ligands, we investigated synthesis of new complexes through thermochemical reactions. Cluster $\mathbf{1}$ on heating at $200^{\circ} \mathrm{C}$ resulted in the formation of de-solvated complex, which on standing at ordinary atmospheric condition at room temperature, slowly absorbs moisture to yield hydrated form. The water absorption process is reversible. The process is illustrated in the three thermograms of the complex after and before heating at $200^{\circ} \mathrm{C}$ (figure 3 ). Since, relatively high thermal stability and reversibility of water binding were observed in these clusters, we determined surface areas of clusters 1 and 4 . The nitrogen adsorption plot of type 2 showing reversibility in nitrogen adsorption were observed. ${ }^{22}$ An illustrative example of the nitrogen adsorption study is shown for the Cluster $\mathbf{1}$ in figure 4. A similar plot for Cluster $\mathbf{4}$ is available as supplementary figure. The surface area for Cluster $\mathbf{1}$ is $8.933 \mathrm{~m}^{2} / \mathrm{g}$; whereas for Cluster 4, the surface area is $6.172 \mathrm{~m}^{2} / \mathrm{g}$ (figure 4).

De-solvation of the Cluster 4, and exchange of solvent by water molecules can be monitored by colour changes in the sample. For example, initial brownishgreen colour of the sample changes to orange on heating which returns to greenish colour on accepting water as illustrated in the photograph of the sample shown in figure 5. Visible spectra of solid samples of $\mathbf{4}$ were recorded and shown as supplementary information figure S12. The anhydrous form has a shoulder at $475 \mathrm{~nm}$ in addition to the parent absorption of solvated form at $400 \mathrm{~nm}$. In a recent study, it has been shown that removal of guest molecules from zinc carboxylate metallo-organic frameworks drastically changes colour. ${ }^{23}$ Such phenomenon arises due to changes in the $\pi$-stacking interactions between the included guests in the host framework, which are involved in ligand to ligand charge transfertransitions. Here, clusters 1-4 have strong $\mathrm{C}-\mathrm{H}^{\cdots} \pi \pi$ interactions, which may be affected by removal of solvent of crystallization, resulting in the observed colour changes. Generally, formation of zinc complexes are guided by solvents; ${ }^{16,27}$ thus, the stability of solvated tetranuclear clusters $\mathbf{1 - 4}$ is of synthetic interest. ${ }^{24-28}$ On the other hand, the formation of the clusters 1-4 were from 1:1 ratio of ligand and metal ion (eq. 1). In an earlier study oxalatebridged tetra-nuclear zinc oxyquinolinate cluster was also prepared from a reaction of zinc(II) ions and 8hydroxyquinoline in 1: 1 molar ratio. ${ }^{21}$ Thus, another product is possible during synthesis of the clusters. The identity of the uncharacterised part in those reactions became obvious when water was used as solvent. When we carried out the reaction of zinc chloride with 8-hydroxyquinoline in aqueous medium, we obtained a complex (HhydroxQ) $)_{2}\left[\mathrm{ZnCl}_{4}\right]$ (5), which has hydroxyquinolinium cation. In aqueous medium, the reaction probably follows eq. (2).

The entire reactions are thus guided by solvents and based on hydrolytic equilibrium of zinc chloride in different solvents. To show the formation of zinc hydroxide in the reaction, we have taken the crude precipitate from the reaction mixture of zinc chloride with 8 -hydroxyquinoline. The precipitate is supposed to comprise complex $\mathbf{5}$ and zinc hydroxide. The crude precipitate was heated at $150^{\circ} \mathrm{C}$ for

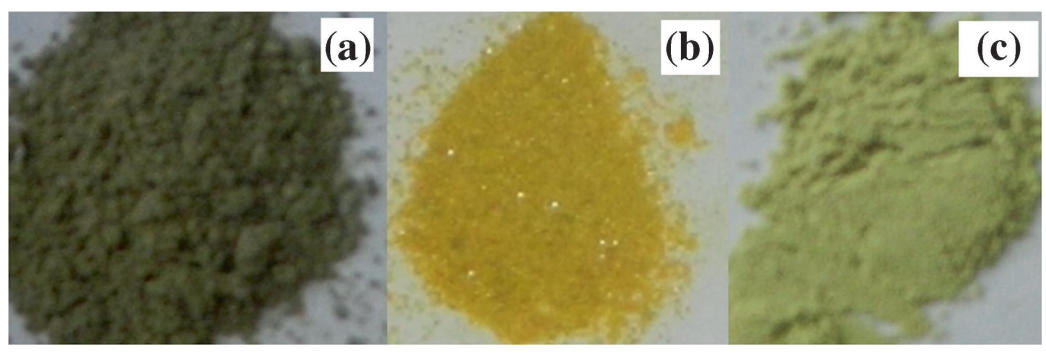

Figure 5. Photographs of powder samples of (a) cluster 4; (b) desolvated cluster $\mathbf{4}$; (c) desolvated cluster $\mathbf{4}$ after absorbing moisture. 


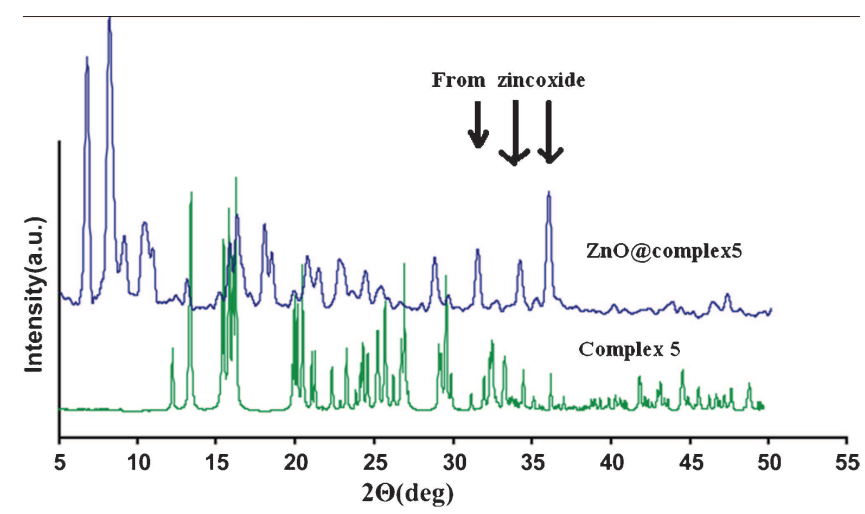

Figure 6. Powder XRD pattern of complex; bottom: 5, top: crude precipitate from the reaction of zinc chloride with 8hydroxyquinoline in water heated at $150^{\circ} \mathrm{C}$ for $12 \mathrm{~h}$ showing the formation of $\mathrm{ZnO} @$ complex 5.

$12 \mathrm{~h}$ and the powder XRD was recorded. The powder XRD was compared with that of complex $\mathbf{5}$ and zinc oxide (figure 6). It was found that powder diffraction pattern contains peaks of zinc oxide. Zinc oxide peaks in the powder XRD patterns are marked with downward arrows. Zinc oxide is generally prepared by overnight heating of zinc hydroxide at around $100^{\circ} \mathrm{C} .{ }^{29}$ On the other hand, complex $\mathbf{5}$ as well as zinc oxide have discernable non-overlapping peaks. Besides, we have also confirmed from thermogram of complex 5 that it does not decompose at $150^{\circ} \mathrm{C}$. The $\left[\mathrm{ZnCl}_{4}\right]^{2-}$ anions are often observed in the reactions of zinc chloride with hydrochloric acid. However, isolation of tetrachloro zinc in the reaction of zinc chloride with quinoline without additional acid is noteworthy. The $\mathrm{Cs}_{2}\left[\mathrm{ZnCl}_{4}\right]$ anion ${ }^{30}$ has $\mathrm{Zn}-\mathrm{Cl}$ bond distances $\sim 2.25 \AA$ with $\mathrm{Cl}-\mathrm{Zn}-\mathrm{Cl}$ angles varying from $106-115^{\circ}$. The structure of complex $\mathbf{5}$ is shown in figure $7 \mathrm{a}$ has similar metal halogen bond parameters as that of the cesium complex reported earlier. In the complex, 8-hydroxyquinolinium cations are held to the anions through $\mathrm{N}-\mathrm{H} \cdots \mathrm{Cl}\left(\mathrm{d}_{\mathrm{H} \ldots \mathrm{Cl}}, 2.35 \AA\right)$ and $\mathrm{O}-\mathrm{H} \cdots \mathrm{Cl}\left(\mathrm{d}_{\mathrm{H} \ldots \mathrm{Cl}}\right.$, $2.30 \AA$ ) interactions. The bond distances are $\mathrm{Zn} 1-\mathrm{Cl} 1$, 2.2632(14); Zn1-Cl2, 2.2771(13); and bond angle of Cl1-Zn1-Cl2 is $111.88(5)^{\circ}$. Thermal stability of the complex 5 was studied by analysing its thermogram. It is found that the complex is less thermally stable than the cluster and decomposes at about $250^{\circ} \mathrm{C}$. The thermogram of complex 5 (Supporting figure S10)

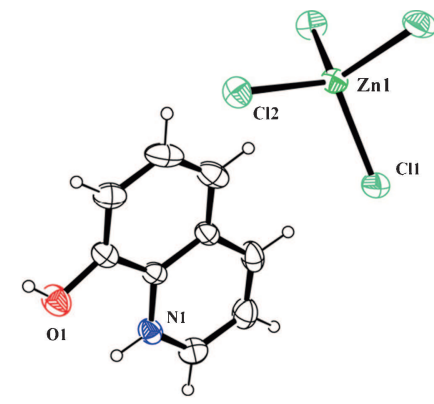

(a)

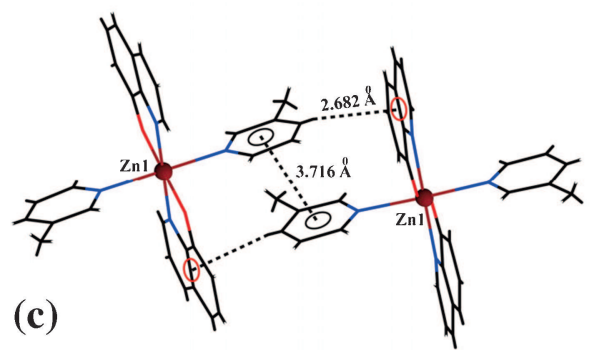

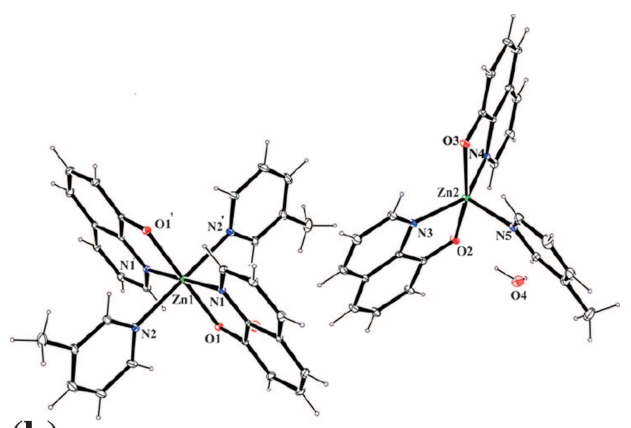

(b)

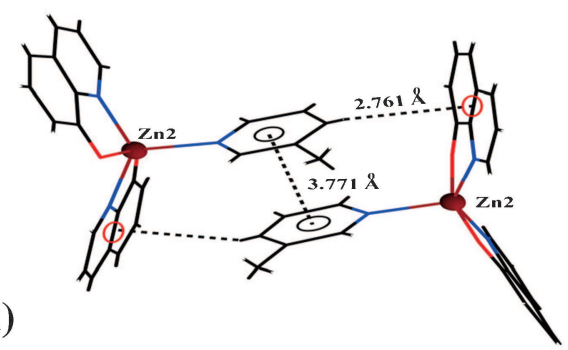

Figure 7. (a) Structure of $(\mathrm{HQ})_{2}\left[\mathrm{ZnCl}_{4}\right]$ (ORTEP drawn with $30 \%$ probability); (b) structure of the molecular complex [Zn(oxyQ $)_{2}(3$ mepy $\left.)\right]$. [Zn $\left.(\text { oxyQ })_{2}(3 \text { mepy })_{2}\right]$. $3 \mathrm{H}_{2} \mathrm{O}$ (6); Some of the selected bond distances ( $\AA$ ) Zn1-O1, 2.053(3); Zn1-N1, 2.145(4); Zn1-N2, 2.275(4); Zn2-N3, 2.076(4); Zn2-O2, 2.062(4); Zn2-O3, 2.059(4); Zn2-N4, 2.903(4); Zn2-N5, 2.080(5); and selected bond angles $\left({ }^{\circ}\right)$ are O1-Zn1N1, 80.90(17); O1-Zn1-N2, 88.99(17); N1-Zn1-N2, 91.33(15); N3-Zn2-N5,103.22(19); N4-Zn2-N5, 115.0(1); O2-Zn2-O3, 162.20(16); O2-Zn2-N3，80.97(18); O2-Zn2-N4, 91.20(17); O2-Zn2-N5, 101.5(1); O3-Zn2-N3， 96.26(17); O3-Zn2-N4, 80.08(17); O3-Zn2-N5, 96.26(19); N3-Zn2-N4, 141.80(17). Molecular complex 6 (ORTEP drawn with $30 \%$ thermal ellipsoids); (c) hexa-coordinated molecules of $\mathbf{6}$; and (d) pentacoordinated molecules of 6 . 
shows that it loses $45.8 \%$ weight in the range of $250-350^{\circ} \mathrm{C}$. This weight loss corresponds to loss of a hydroxyquinoline and two hydrochloric acid molecules (theoretical 43.7\%). On further heating, the complex loses weight in the region from $450^{\circ} \mathrm{C}$ to $700^{\circ} \mathrm{C}$ and gives a residue having composition $\mathrm{ZnClO}_{0.5}$ (theoretical weight loss $78.9 \%$, experimental weight loss $79.2 \%$ ). This suggests that when (HhydroxQ) ${ }_{2}\left[\mathrm{ZnCl}_{4}\right]$ is heated, it initially forms [(hydroxQ) $\mathrm{ZnCl}_{2}$ ] which is above $450^{\circ} \mathrm{C}$ forms dinuclear $\mathrm{Zn}_{2} \mathrm{OCl}_{2}$.

$$
\begin{aligned}
2 \text { hydroxQ } & +2 \mathrm{ZnCl}_{2}+2 \mathrm{H}_{2} \mathrm{O} \rightarrow(\text { HhydroxQ })_{2}\left[\mathrm{ZnCl}_{4}\right] \\
& +\mathrm{Zn}(\mathrm{OH})_{2}
\end{aligned}
$$

We were interested in modifying the clusters to prepare covalently linked framework structures. Thus, various reactions of 8-hyrdoxyquinoline in presence of pyridine and its derivatives were carried out. We could obtain a crystalline material from the reaction of 8-hydroxyquinoline with zinc chloride and 3-methylpyridine. However, we observe a molecular complex of two mononuclear neutral complexes. The complexes were devoid of chloride. The two neutral complexes forming molecular complex has composition $\left[\mathrm{Zn}(\text { oxyQ })_{2}(3\right.$ mepy $\left.)\right]$ and [ $\left.\mathrm{Zn}(\text { oxyQ })_{2}(3 \text { mepy })_{2}\right]$ (where 3mepy $=3$-methylpyridine) (figure $7 \mathrm{~b}$ ). The first part adopts a five coordinate distorted square pyramid structure, whereas the other part has distorted octahedral geometry. The part having octahedral structure has a mirror plane bisecting the half of the molecule. The bond distances and bond lengths contributing to molecular complex are listed in figure $7 \mathrm{~b}$ caption. The part of the molecular complex with octahedral geometry has two 3-methylpyridines at two apices and they are trans to each other. Comparing the axial $\mathrm{Zn}-\mathrm{N}$ bonds in two geometries namely Zn1-N2, 2.275(4) and Zn2-N5, 2.080(5), it may be suggested that the 3-methylpyridine molecule is more tightly bound in penta-coordinate geometry than hexa-coordinate geometry. Earlier, we have shown molecular complexes of dissimilar zinc complexes between trinuclear and dinuclear combinations; and between tetra-coordinate and hexa-coordinate zinc complexes. ${ }^{31,32}$ Here, a pentacoordinated complex and a hexa-coordinated complex, independently self-assemble through weak interactions and are arranged in the form of layers. While forming a layer, each pair of complexes is interconnected through intervening lattice water molecules.

The coordination polymers and MOF which have connecting zinc ions, show photoluminscent properties. ${ }^{33-36}$ On the other hand, quinoline is a fluorescence active compound generally used for detecting metal ions and as probes. ${ }^{37,38}$ Fluorescence emission spectra of each solid sample of the complexes by exciting at $390 \mathrm{~nm}$ were recorded (figure 8a). From the observed pattern of fluorescence emission intensity, there is no clear correlation of the emission properties with the solvent of crystallization. Among the clusters, the DMA and DMF clusters have shown quenching with respect to 8-hydroxyquinoline, whereas the DMSO containing cluster 3 shows slight enhancement of fluorescence and emission shift towards higher wavelength, which occurs at $495 \mathrm{~nm}$. The 8-hydroxyquinoline in solid state has fluorescence emission at 480 $\mathrm{nm}$. These observations clearly indicate the role of interstitial solvent in guiding the fluorescence. Similar observations of change of fluorescence intensities in zinc metallo-organic frameworks with inclusion of aromatic compounds were observed. ${ }^{23}$ Molecular complex 6 shows the highest emission, whereas the DMF and DMA containing clusters $\mathbf{1}$ and $\mathbf{2}$ show the lowest emission. We have observed dual emission for the sample of $\mathrm{ZnO}$ doped into complex 5, which was studied in the form of $\mathrm{ZnO@complex} 5$ (figure 8b). ZnO@complex 5 exhibits emissions at $575 \mathrm{~nm}$ and $450 \mathrm{~nm} ; 575 \mathrm{~nm}$ is relatively higher wavelength than parent compounds
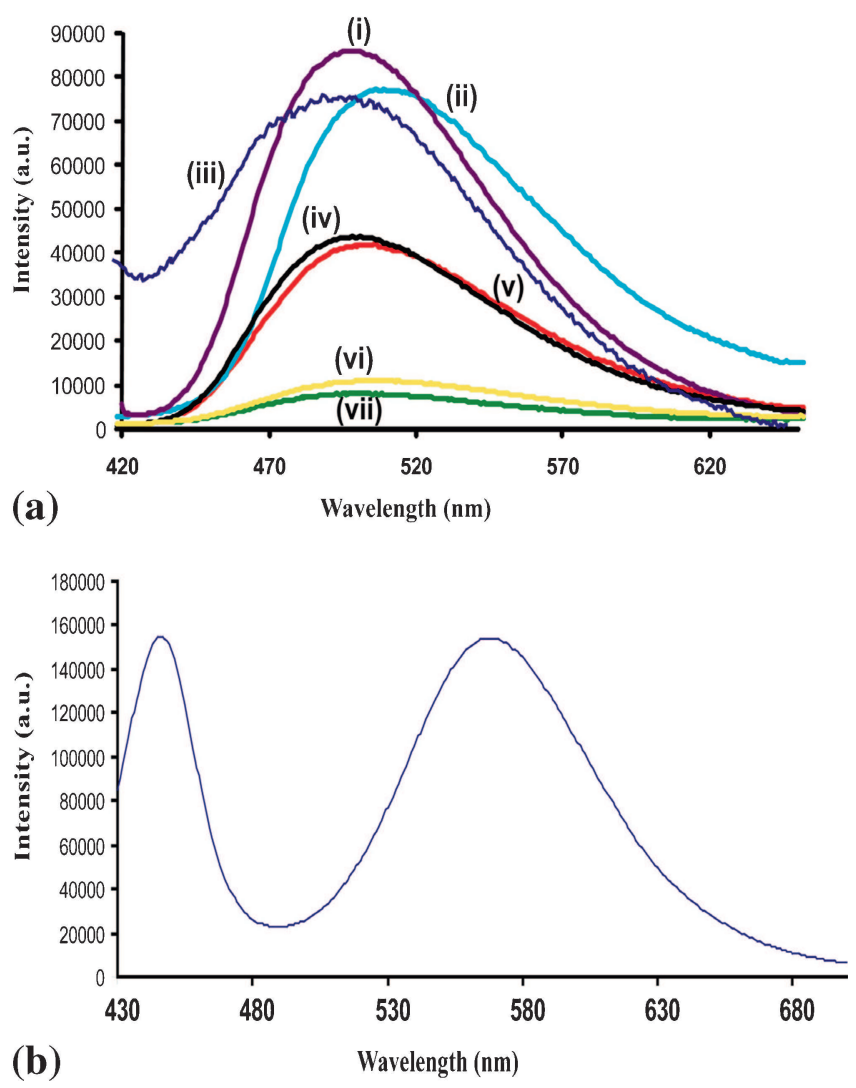

Figure 8. (a) Fluorescence emission of the solid samples of complex (i) $\mathbf{6}$; (ii) 3; (iii) 8-hydroxyquinoline; (iv) 5; (v) 4; (vi) 2 (vii) 1 ( $\lambda_{\text {ex }}=390 \mathrm{~nm}$ ). (b) Fluorescence emission of $\mathrm{ZnO} @$ complex 5. 
and $450 \mathrm{~nm}$ is relatively shorter wavelength than 8hydroxyquinoline or complex $5(495 \mathrm{~nm})$. This is an example of a composite materials showing dual fluorescence, which may have practical applications. Thus observation of dual fluorescence at such high wavelength is of definite interest. ${ }^{39,40}$

\section{Conclusions}

We are able to show that different metal complexes are generated from 1:1 reactions of zinc chloride with 8-hydroxyquinoline. Hydrolytic instability of zinc chloride, has helped in precipitation of a tetrachlorozincate complex along with zinc hydroxide. This has enabled us to prepare zinc oxide within the matrix of complex 5. Molecular complex 6 is a rare examples providing opening for studies of such complexes.

\section{Supplementary Information}

Experimental and simulated powder XRD patterns of all the clusters and complexes, IR spectra of cluster 4 before and after heating, nitrogen absorption isotherm of cluster $\mathbf{4}$, Thermogravimetry of clusters, bond parameters cluster 1-4 and complex $\mathbf{5}$ are available as supporting information.

The supplementary information (figures S1-S12 and tables S1-S2) can be seen at www.ias.ac.in/chemsci.

\section{References}

1. Erxleben A 2003 Coord. Chem. Rev. 246203

2. Zheng Q, Yang F, Deng M, Ling Y, Liu X, Chen Z, Wang Y, Weng L and Zhou Y 2013 Inorg. Chem. 5210368

3. Qi Y, Che Y X and Zheng J M 2008 Cryst. Eng. Comm. 101137

4. Granifo J, Garland M T and Baggio R 2006 Polyhedron 252277

5. Toh N L, Nagarathinam M and Vittal J J 2005 Angew. Chem. Int. Ed. Eng. 442237

6. Williams C A, Blake A J, Hubberstey P and Schroder M 2005 Chem. Commun. 5435

7. Yaghi O M, O'Keeffe M, Ockwig N W, Chae H K, Eddaoudi M and Kim J 2003 Nature 423705

8. Eddaoudi M, Moler D B, Li H, Chen B, Reineke T M, O'Keeffe M and Yaghi O M 2001 Acc. Chem. Res. 34 319

9. Eddaoudi M, Li H, Reineke T, Fehr M, Kelley D, Groy T L and Yaghi O M 1999 Top. Catal. 9105

10. Kumar U, Thomas J and Thirupathi N 2010 Inorg. Chem. 4962

11. Hou L, Lin Y Y and Chen X M 2008 Inorg. Chem. 47 1346
12. Gao W Y, Yan W, Cai R, Meng L, Salas A, Wang X S, Wojtas L, Shi X and Ma S 2012 Inorg. Chem. 514423

13. He K H, Li Y W, Chen Y Q, Song W C and Bu X H 2012 Cryst. Growth Des. 122730

14. Zhao X, Xiao B, Fletcher A, Thomas K M, Bradshaw D and Rosseinsky M J 2004 Science 3061012

15. Cui Y, Yue Y, Qian G D and Chen B L 2012 Chem. Rev. 1121126

16. Karmakar A and Baruah J B 2008 Polyhedron 273409

17. Donze N, Pechy P, Gratzel M, Schaer M and Zuppiroli L 1999 Chemical Physics Letters 315405

18. Rawat M, Prakash S, Singh C and Anand R S 2011 AIP Conf. Proc. 1391187

19. Sokolowski K, Justyniak I, Sliwinski W, Soltys K, Tulewicz A, Kornowicz A, Moszynski R, Lipkowski J and Lewinski J 2012 Chemistry 185637

20. Sattarzadeh E, Mohammadnezhad G, Amini M M and Ng S W 2009 Acta Cryst. E65 m712

21. Wang J, Wang Q, Sun Y, Wang Y, Zhao G and Cui Y 2011 J. Serb. Chem. Soc.76 529

22. Sing K S W, Everett D H, Haul R A W, Moscou L, Pierotti R A, Rouquerrol J and Siemieniewska T 1985 Pure and Appl. Chem. 57603

23. Pramanik S, Zheng C, Zhang X, Emge T J and Li J 2011 J. Am. Chem. Soc. 1334153

24. Holland D R, Hausrath A C, Juers D and Matthews B W 1995 Protein Sci. 41955

25. Tamilselvi A and Mugesh G 2008 J. Biol. Inorg. Chem. 131039

26. Singh W M and Baruah J B 2009 Dalton Trans. 2352

27. Sarma R, Kalita D and Baruah J B 2009 Dalton Trans. 7428

28. Bury W, Justyniak I, Prochowicz D, Rola-Noworyta A and Lewinski J 2012 Inorg. Chem. 517410

29. Kolodziejezak-Radzimska A and Jesionowski T 2014 Materials 72853

30. McGinnety J A 1974 Inorg. Chem. 131057

31. Phukan N and Baruah J B 2013 RSC Advances 31151

32. Karmakar A, Sarma R J and Baruah J B 2006 Inorg. Chem. Commun. 91169

33. Cui J, Lu Z, Li Y, Guo Z and Zheng H 2012 Chem. Commun. 487967

34. Xu H, Liu F, Cui Y, Chen B and Qian G 2011 Chem. Commun. 473153

35. Lan A, Li K; Wu H, Olson D H, Emge T J, Ki W, Hong $\mathrm{M}$ and Li J 2009 Angew. Chem. Int. Ed. Eng. 482334

36. Fletcher A J, Thomas K M and Rosseinsky M J $2005 \mathrm{~J}$. Solid State Chem. 1782491

37. Chen Y, Wang H, Wan L, Bian Y and Jiang J $2011 \mathrm{~J}$. Org. Chem. 763774

38. Fahrni C J and O'Halloran T V 1999 J. Am. Chem. Soc. 12111448

39. Shynkar V V, Klymchenko A S, Piemont E, Demchenko A P and Mely Y 2004 J. Phys. Chem. A. 1088151

40. Klymchenko A S and Demchenko A P $2002 \mathrm{~J}$. Am. Chem. Soc. 12412372

41. CrysAlisPro 2009 Oxford Diffraction Ltd. version 1, 171. 33.34d

42. Sheldrick G M 2008 Acta Crystallogr. A64 112 